Roy G. Brower

\title{
Time to reach a new equilibrium after changes in PEEP in acute respiratory distress syndrome patients
}

Received: 21 June 2013

Accepted: 5 August 2013

Published online: 20 August 2013

(C) Springer-Verlag Berlin Heidelberg and ESICM 2013

R. G. Brower (匹)

Pulmonary and Critical Care Medicine,

Johns Hopkins University School of Medicine,

1800 Orleans Street, Baltimore, MD 21205, USA

e-mail: rbrower@jhmi.edu

Tel.: +1-410-6146292

Fax: +1-443-6830336

In patients with acute respiratory distress syndrome (ARDS), some alveoli and small bronchi collapse because of high surface tension at air-liquid interfaces [1]. Other alveoli and small airways may flood with liquid that leaked from the vascular space [2]. The resulting intrapulmonary shunt may cause life-threatening hypoxemia. Positive endexpiratory pressure (PEEP) prevents collapse of some alveoli and redistributes liquid in airspaces, restoring aeration of other alveoli [3-6]. Also, preventing airway collapse and maintaining larger aerated portions of the lung can reduce injurious stresses in the lungs during ventilation [7]. However, PEEP may also increase stress and strain in the lung during inspiration and cause circulatory depression [8]. Unfortunately, practical methods for optimizing PEEP in individual patients have been difficult to find.

In a recent issue of Intensive Care Medicine, Chiumello and colleagues [9] provided useful information on important but frequently overlooked questions: What is the time-course of changes in gas exchange, circulation, and lung mechanics after PEEP is increased or decreased within a range that is commonly used in ARDS patients? How long must we wait before there is a new equilibrium? When can we assess whether gas exchange or lung mechanics is adequate or acceptable, or if we must do something else, such as raising or lowering PEEP further or proning [10]. In 44 ARDS patients, when PEEP was decreased (from 15 to 10 or from 15 to $5 \mathrm{cmH}_{2} \mathrm{O}$ ), changes in oxygenation variables were complete within $5 \mathrm{~min}$; respiratory system compliance decreased slowly and modestly over $60 \mathrm{~min}$. When PEEP was raised (from 10 to 15 and from 5 to $15 \mathrm{cmH}_{2} \mathrm{O}$ ), changes in oxygenation variables appeared not to have reached equilibrium after $60 \mathrm{~min}$; changes in respiratory system compliance were complete within 5-10 min. Ventilation variables, cardiac output, mean arterial pressure, and heart rate showed little to no effect with changes in PEEP. Clinicians can use these data to make more deliberate adjustments to PEEP while trying to balance the potential risks and benefits of the numerous variables that they must consider. Clinical researchers can use these data to improve protocols of new strategies for optimizing mechanical ventilation.

There are some limitations to the applicability of the data in this study. All patients were paralyzed with vecuronium. The time-course of changes after PEEP adjustments may be different in patients who can cough, shift their weight in bed, take deep breaths or stack breaths, or contract their inspiratory and expiratory muscles. Also, recruitment maneuvers were conducted in this study before the beginning of the first PEEP change. This could have altered the opening and closing characteristics of some lung units.

From a physiologist's point of view, it is especially interesting to consider why the time-course of the oxygenation variables was so different comparing PEEP increases with PEEP decreases; For example, when PEEP was decreased from 15 to $5 \mathrm{cmH}_{2} \mathrm{O}$, mean $\mathrm{PaO}_{2}$ decreased from 107 to $75 \mathrm{mmHg}$ within $5 \mathrm{~min}$ and then varied very little over the subsequent $55 \mathrm{~min}$. In contrast, when PEEP was increased from 5 to $15 \mathrm{cmH}_{2} \mathrm{O}, \mathrm{PaO}_{2}$ increased from 76 to $92 \mathrm{mmHg}$ after $5 \mathrm{~min}$ and then increased further to 97 (15 min), 103 (30 min), and $108 \mathrm{mmHg}$ (60 min). 
When PEEP is lowered, derecruitment may involve occlusions of segments of small airways by liquid [11]. "Liquid bridges" may occur at several or many discrete loci between the larger airways and alveoli. Several factors could determine whether and where these bridges occur, including airway diameter and surface tension, and viscosity and volume of fluid in the airspaces [11, 12]. The liquid bridges may not form at the same time, but once a single bridge forms, the alveoli subtended by the bridged bronchus would be lost to ventilation, leading to atelectasis, shunt, and decreased lung compliance. The effects on oxygenation and lung compliance would begin when the first bronchial segment becomes occluded. Therefore, the changes in oxygenation variables and respiratory system compliance should occur quickly.

When PEEP is increased, recruitment may involve a sequence of breaking of liquid bridges, starting with the liquid bridges in the largest of the small airways, because these bridges would be the first to be subjected to the higher airway pressure. Once this liquid bridge breaks, the higher airway pressure could then advance to the next liquid bridge. If the airway pressure is high enough, it could break an entire sequence of bridges until it reaches the alveoli. Branch points along the way would give rise to generations of smaller daughter airways, some of which may have additional liquid bridges to break. The increasing number of branching, opening pathways has been compared to an avalanche, leading ultimately to large numbers of alveoli [13]. If an alveolus is flooded, the higher airway pressure may cause the fluid to redistribute, allowing aeration. If it is closed, it may have its own opening pressure, and it may open and become aerated. Another force for recruitment is the interdependence between neighboring regions of lung [14]. If an increase in airway pressure leads to aeration of one region but not an adjacent region (because the latter's opening pressures were too high), the tension in the parenchyma between the adjacent units may lead to opening of the stubborn, closed area. Finally, additional recruitment could occur through collateral ventilation, perhaps through pores of Kohn [15] or other nonbronchial channels. Thus, it is not difficult to imagine that the process of recruitment would take longer than the process of derecruitment.
However, data from experimental models suggest that recruitment occurs as quickly or even more quickly than derecruitment [16-20]; For example, in rat lungs after bronchoalveolar lavage, approximately $80 \%$ of the potential recruitment occurred within several seconds, and recruitment appeared to be complete within $40 \mathrm{~s}$ [17]. In mice with acid-induced lung injury, the velocity of opening was an order of magnitude greater than the velocity of closing [18]. In three different porcine models of acute lung injury, time constants of recruitment and derecruitment (assessed by dynamic computerized tomographic scanning) were mostly in the range of $0-2 \mathrm{~s}[16,19]$.

Then why was the time-course of the oxygenation variables in the current study by Chiumello and colleagues so much longer after a PEEP increase than after a PEEP decrease? One explanation could be that there are differences in the lung mechanics of different species. Another possible explanation is that the improvement in oxygenation variables between 5 and $60 \mathrm{~min}$ after a PEEP increase was not due to additional lung recruitment. Respiratory system compliance should increase over time if there is additional recruitment after $5 \mathrm{~min}$, but this did not occur in the study by Chiumello and colleagues. Given the trivial changes in arterial $\mathrm{PCO}_{2}$ after PEEP increases, we cannot attribute improved arterial oxygenation to improved ventilation. Increased diffusing capacity is also implausible. Perhaps the sustained increase in PEEP and associated higher inspiratory pressures caused a gradual stress relaxation of airways and parenchyma, leading to improvements in ventilationperfusion matching.

Regardless of the physiologic mechanisms behind the results of this study, the data provide useful information to help clinicians and researchers make decisions. Understanding the physiology makes it more interesting and, ultimately, will allow us to take additional steps towards optimizing our approaches to mechanical ventilation in ARDS patients.

Acknowledgments I thank John Marini, Rolf Hubmayr, Art Slutsky, and Jason Bates for useful discussions regarding the physiology of recruitment and derecruitment.

\section{References}

1. Ware LB, Matthay MA (2000) The acute respiratory distress syndrome. N Engl J Med 342:1334-1349

2. Stuber F, Petersen M, Bokelmann F, Schade U (1996) A genomic polymorphism within the tumor necrosis factor locus influences plasma tumor necrosis factor-alpha concentrations and outcome of patients with severe sepsis. Crit Care Med 24:381-384
3. Ashbaugh DG, Petty TL, Bigelow DB, Harris TR (1969) Continuous positivepressure breathing (CPPB) in adult respiratory distress syndrome. $\mathrm{J}$ Thorac Cardiovasc Surg 57:31-41

4. Halter JM, Steinberg JM, Schiller HJ et al (2003) Positive end-expiratory pressure after a recruitment maneuver prevents both alveolar collapse and recruitment/derecruitment. Am J Respir Crit Care Med 167:1620-1626
5. Schiller HJ, McCann UG, Carney DE, Gatto LA, Steinberg JM, Nieman GF (2001) Altered alveolar mechanics in the acutely injured lung. Crit Care Med 29:1049-1055

6. Malo J, Ali J, Wood LDH (1984) How does positive end-expiratory pressure reduce intrapulmonary shunt in canine pulmonary edema? J Appl Physiol 57:1002-1010 
7. Gattinoni L, Carlesso E, Cadringher P, Valenza F, Vagginelli F, Chiumello D (2003) Physical and biological triggers of ventilator-induced lung injury and its prevention. Eur Respir J Suppl 47:15s-25s

8. Pinsky MR (1997) The hemodynamic consequences of mechanical ventilation: an evolving story. Intensive Care Med 23:493-503

9. Chiumello D, Coppola S, Froio S et al (2013) Time to reach a new steady state after changes of positive end expiratory pressure. Intensive Care Med 39:13771385. doi:10.1007/s00134-013-2969-x

10. Guerin C, Reignier J, Richard JC et al (2013) Prone positioning in severe acute respiratory distress syndrome. N Engl J Med 368:2159-2168

11. Hubmayr RD (2002) Perspective on lung injury and recruitment: a skeptical look at the opening and collapse story. Am J Respir Crit Care Med 165:1647-1653
12. Bates JH, Irvin CG (2002) Time dependence of recruitment and derecruitment in the lung: a theoretical model. J Appl Physiol 93:705-713

13. Suki B, Barabasi A-L, Hantos Z, Petak F, Stanley HE (1994) Avalanches and power-law behaviour in lung inflation. Nature 368:615-618

14. Mead J, Takishima T, Leith D (1970) Stress distribution in lungs: a model of pulmonary elasticity. J Appl Physiol 28:596-608

15. Namati E, Thiesse J, de RJ, McLennan G (2008) Alveolar dynamics during respiration: are the pores of Kohn a pathway to recruitment? Am J Respir Cell Mol Biol 38:572-578

16. Markstaller K, Eberle V, Kauczor HU et al (2001) Temporal dynamics of lung aeration determined by dynamic CT in a porcine model of ARDS. Br J Anaesth 87:459-468
17. Albert SP, DiRocco J, Allen GB et al (2009) The role of time and pressure on alveolar recruitment. J Appl Physiol 106:757-765

18. Massa CB, Allen GB, Bates JH (2008) Modeling the dynamics of recruitment and derecruitment in mice with acute lung injury. J Appl Physiol 105:1813-1821

19. Neumann P, Berglund JE, Mondejar EF, Magnusson A, Hedenstierna G (1998) Dynamics of lung collapse and recruitment during prolonged breathing in porcine lung injury. J Appl Physiol 85:1533-1543

20. Neumann P, Berglund JE, Mondejar EF, Magnusson A, Hedenstierna G (1998) Effect of different pressure levels on the dynamics of lung collapse and recruitment in oleic-acid-induced lung injury. Am J Respir Crit Care Med 158:1636-1643 